\title{
La mujer y la naturaleza en Terra baixa de Àngel Guimerà, en la ópera Tiefland de Eugen d'Albert y Rudolph Lothar y en el film Tiefland de Leni Riefenstahl
}

\author{
MARIDÈS SOLER \\ Universidad de Tréveris
}

\begin{abstract}
Resumen
En este estudio se investiga la trasposición del drama rural catalán Terra baixa, de Àngel Guimerà, en la ópera verista y en la película del mismo nombre, ambas alemanas. Además de las peculiaridades inherentes a cada medio, se analiza en detalle el papel de la mujer y de la naturaleza (animales, montañas, agua, temporal) teniendo en cuenta las perspectivas y expectaciones de la sociedad de cada época ante esos temas, desde el estreno del drama en 1897 hasta el del film de 1953.
\end{abstract}

Palabras clave: Àngel Guimerà, Eugen d'Albert, Leni Riefenstahl, Terra baixa, Tiefland

\begin{abstract}
This article studies the transposition of the Catalan rural play Terra baixa, by Àngel Guimerà, into the German Verismo oper and the film of the same name. Besides the typical peculiarities of each medium, it will be analized woman's and nature's (animals, mountains, water, tempest) role too. Together with the respective adaptations, it will be taken into consideration the view of the society before these subjects since the première of the drama in 1897 until that of the film in 1954.
\end{abstract}

Key words: Àngel Guimerà, Eugen d'Albert, Leni Riefenstahl, Terra baixa, Tiefland 
$\mathbf{T}$

oda obra literaria puede ser traspuesta a otros medios, sobre todo los textos escritos para un sistema dramatúrgico. En la ópera y el film, el argumento se basará en un libreto o un guion y el resultado será un producto final completamente distinto al del texto originario con motivo de las peculiaridades típicas de cada género, pero conservando el mismo impacto. El paso de un medio al otro se halla sujeto a diferentes normas, que estudiaremos a continuación de una manera sumaria:

1. De todos los géneros literarios, el teatro es el más adecuado para hacer adaptaciones de ópera (Fricke, 1985: 95; Kaindl, 1995: 60) o cine. La ópera no se reduce solamente al canto, pues también consta de "cuadros músico-escénicos", en los que las palabras y la escenificación se hallan íntimamente entrelazados. Ya que para cantar se necesita más tiempo que para hablar y a menudo se repite el texto, el libreto tendrá que ser necesariamente más breve que una obra teatral. Lindenberger ve cierto paralelismo entre la adaptación de una obra para la ópera y para el cine, ya que en ambos tiene lugar un empobrecimiento del texto de partida. Por su parte, el film presenta unas características específicas más cercanas a la fotografía, por lo que la misma Riefenstahl lo definió con acierto como figuras en movimiento (1987: 333-334) acompañadas por sonido y música. ${ }^{1}$

2. Existe una gran diferencia entre la posición de un dramaturgo y el de un libretista o guionista. El dramaturgo, el compositor y el director de cine gozan de gran reputación a diferencia de los libretistas y guionistas, quienes a menudo restan anónimos aunque a veces sus honorarios suelen ser mucho más lucrativos (Manvell, 1979: 29). Por su parte, una obra de teatro puede ser también leída, mientras que los libretos y guiones, normalmente ni siquiera son editados y sólo sirven para el uso exclusivo de los actores. La finalidad primordial del libreto, lo mismo que la del guion, es la de servir de base para la música o para la película (Hacks, 1980: 238). Al final, la calidad de una ópera se medirá por la música o la escenografía y la de una película por su conjunto, del cual sólo es responsable

1 El 1939 Riefenstahl impartió en París una conferencia sobre el cine: Ist Film Kunst?, en la que pregona la paridad del cine con las otras artes tradicionales y define el arte cinematográfico como filmisch (1987: 333-335). 
el director, quien primero se convertirá en el "autor" inicial y, al final, como un deus ex machina, en el autor indiscutible del film (Manvell, 1979: 47).

3. Una obra teatral se basa sobre todo en el diálogo, el cual es hablado en un tono más elevado que el normal. Los diálogos y la presencia física de los actores contribuyen a electrizar directamente a los espectadores, si bien en la ópera, a diferencia del teatro, el número de personajes es más reducido; al contrario, una película ofrece más posibilidades de presentar un elenco más amplio. En la ópera, el canto sustituye al diálogo, mientras que en el cine, los diálogos constituyen sólo una parte del comportamiento de un protagonista y el tono es el de una conversación normal sin tener aspiraciones literarias (Manvell 1979: 25, 32); en el film, más importante que el diálogo es el comportamiento total del protagonista junto con su quinesia facial y corporal, a la vez que la cámara acentúa cada detalle del actor con escenas de primer plano (Manvell, 1979: 32). En una película, las vistas tienen más importancia que los diálogos, los cuales son imprescindibles en un drama. ${ }^{2}$

4. Las obras de teatro y las óperas se reducen al escenario, mientras que una película se puede rodar en cualquier lugar fuera de este. Los límites del teatro son los bastidores y los del cine la realidad (Diederichs, 1994: 163), lo que significa que esos límites son ilimitados.

5. En el teatro y la ópera tiene lugar un encuentro y una interacción entre la obra, los actores y el público (Manvell, 1979: 15). Teatro yópera son espectáculos en directo, es decir, los actores se encuentran físicamente presentes y, aunque en cada representación repiten siempre el mismo texto, pueden percatarse de las reacciones del público y tienen la libertad de introducir ad hoc algún cambio para captar mejor la atención de aquel. En el teatro, el argumento es más flexible que en el cine, que es más perfeccionista en cada detalle, y una vez terminado el rodaje, la representación es siempre la misma y ya no se puede introducir ningún cambio posterior, por lo que Manvell compara una película con un

2 Una cámara puede captar vistas en detalle de una parte de la naturaleza total desde insectos microscópicos hasta tomas panorámicas (Bentley, 1974: 57). 
cuadro o una estatua, es decir con una obra de arte definitivamente acabada (Manvell, 1979: 24). ${ }^{3}$

6. Por su parte, los espectadores ven la obra a través de sus propios ojos mientras que en el cine será únicamente a través del ojo de la cámara, si bien tanto los personajes como la acción puedan ser observados más de cerca que en el teatro (Manvell, 1979: 35). El film es la proyección de una actuación en conserva filmada sin audiencia, pero que una vez terminado será una única representación para todo el mundo. Al final tanto el director como los actores verán el film completo por primera vez, ya que una película es el resultado de un proceso de infinitas revisiones de la pieza original a fin de encontrar la forma más adecuada. Por otra parte, muchos actores de cine pueden actuar sin ser profesionales (Manvell, 1979: 25), tal como fue el caso de Pedro de Tiefland.

6. Una obra teatral no acostumbra a estar acompañada de música de fondo; por el contrario, la música constituye el elemento esencial de la ópera y también jugará un papel importante en una película (Manvell, 1979: 23, 26), lo cual a veces llega a adquirir protagonismo propio o contribuye a realzar el suspense de la acción. Sin embargo, a veces la mejor música fílmica es la que apenas se percibe, y la misma Riefenstahl comentó que a veces por ser demasiado alta puede resultar insoportable (Manvell, 1979: 335). Al igual que los libretistas y guionistas, con pocas excepciones (Moricone, Rota) los compositores de música fílmica apenas son conocidos.

\section{Terra baixa. Tiefland}

De las innumerables obras teatrales de Àngel Guimerà (1845-1924), ${ }_{4}^{4}$ Terra baixa (1897) es la que más se ha representado y más fama internacional le ha dado. Se trata de un drama rural y, a diferencia de otros escritores catalanes de su época (Víctor Català [Caterina Albert], Raimon Casellas), quienes consideraban la

3 En este contexto también cabe tener en cuenta el género híbrido de las filmaciones televisivas de obras teatrales u operísticas.

4 En su época Guimerà fue conocido como el "Shakespeare catalán”, y en 1903 fue nombrado candidato para el premio Nobel, el cual fue repartido entre José Echegaray y Fréderic Mistral. 
naturaleza como un elemento amenazador, Terra baixa ofrece una relación positiva frente a las montañas (Neumann, 1999: 78).

La compañía de María Guerrero dio a conocer el teatro guimeraniano por Europa y América, pero el paso de la obra teatral a la ópera fue debido a la pura casualidad. Una condesa húngara, que la había visto, deseó representarla ella misma y pidió que la tradujesen al alemán. Más tarde ya se había casado y no quiso saber más de ella. No obstante, los traductores enviaron esa copia a la Ópera Real de Dresde, donde fue a parar por azar a las manos del director Ernst von Schuch, quien se entusiasmó enseguida con ella y pidió a Eugen d'Albert (1864-1932) que la musicalizara con el libretista Rudolph Lothar (1865-1943). D’Albert y Lothar introdujeron algunos cambios necesarios para la adaptación al teatro musical; por ejemplo, comprimieron el argumento y redujeron el número de personajes y escenas. El resultado fue la ópera más importante del verismo alemán, que todavía se representa hoy en los teatros alemanes. ${ }^{5}$ Tanto la ópera como el film han introducido un prólogo situado en la alta montaña con motivos de música alpina, por lo que Tiefland (1903) se alinea en la tradición de las óperas alpinas, que surgieron ya a finales del siglo XVIII bajo la influencia de Rousseau (Neumann, 199: 146). Ya desde su estreno pronto conoció un gran éxito y en la época nazi fue muy popular, ya que en parte respondía a sus ideales de naturaleza impoluta, hombre joven fuerte y sano y su lucha contra el Mal.

El 1934 Terrace Films había encargado a Riefenstahl (1902-2003) que filmase esta ópera con ella como protagonista principal. Al final ella misma

5 En la temporada del 1907-1908 se representó más de cien veces sólo en la Komische Oper de Berlín, con la escenificación de H. Gregor y 463 en el resto de Alemania; en la temporada del 1908-1909 fueron un total de 647. En la actualidad todavía es representada con frecuencia en los teatros alemanes; por ejemplo, el 26 de marzo de 2011 fue dirigida por Katharina Wagner, la nieta de Richard Wagner, en Maguncia con una puesta en escena postmoderna, que tuvo una resonancia encontrada. Normalmente las escenografías modernas de las óperas veristas no suelen ser bien acogidas por el público, por ejemplo, un caso extremo fue la de G. Lohse de Klagenfurt (1992), quien recurrió a un rascacielos como substituto moderno de las montañas. Sobre escenografías modernas de Tiefland véase Neumann, 1999: 159-162. En agosto del 2011 "La Fura dels Baus" estrenó Terra baixa reloaded en la sala gótica de la Biblioteca de Catalunya acompañada con la proyección en tres pantallas de la película Terra baixa de Isidro Ortiz 
escribió también el guion como suele suceder a menudo entre directores de cine (Manvell 1979: 30). Sin embargo, a excepción de Wagner o Rimski-Korsakov, pocos han sido los compositores, quienes han escrito ellos mismos el libreto (Raupp 1930: 341; Pangels, 1981: 391). Por su temática, Tiefland (1933-1954) se alinea en la tradición de las películas de montaña alemanas, cuyo iniciador fue Arnold Fanck (Spaich 1994: 112), ${ }^{6}$ con quien Riefenstahl trabajó al principio como artista y más tarde aprendió el arte de directora de cine. Pronto pasó a dirigir sus propias películas ejerciendo ella misma el papel de protagonista, siendo su principal film Das blaue Licht (1932). Su última película fue Tiefland, que no es muy conocida y normalmente se deja de lado por no encajar ni en los clichés de película nazi ni tampoco en los de película de montaña.

Al principio había pensado rodarla en España y el 1934 fue allá para buscar un set adecuado, pero cuando Terrace Films no le envió más dinero, tuvo que abandonar ese proyecto. Años más tarde (1939), mientras preparaba la preproducción de Pentesilea (Riefenstahl, 1987: 215-216), estalló la Segunda Guerra Mundial, por lo que tuvo que interrumpir ese ambicioso proyecto y volvió a ocuparse de Tiefland. Guimerà la situó en su época en la tierra baja de Cataluña; d'Albert y Lothar, en parte, en un pasto de los Pirineos y, en parte, al pie de estos, sin precisar los años; y Riefenstahl, en el tiempo de Goya (Riefenstahl, 1987: 216) en la provincia de Huesca, ya que el padre de Amelia es el alcalde de esta ciudad, si bien al final la rodó en el macizo de Karwendel (Dolomitas). Por motivos bélicos y posbélicos (Riefenstahl, 1987: 400) se estrenó el 1954 en Stuttgart y fue presentada el mismo año fuera de concurso en Cannes bajo la presidencia de Jean Cocteau, quien comentó: "Las imágenes irradian una intensidad como de Breughel, inalcanzable es la poesía de la cámara y la película tiene estilo" (cit. en Riefenstahl, 1987: 527). Riefenstahl buscaba para algunas escenas dos tipos básicos de referentes: la pintura española del siglo XVIII, sobre todo de Goya (tierra baja), y las pinturas románticas alemanas (tierra alta), especialmente las de Caspar David Friedrich (Quintana y Casacuberta, 2002: 10). Los diálogos son breves y cortos, lo mismo que en Das blaue Licht,

6 Las películas de Fanck se basaban en el principio de "der kleine Mensch und der grosse Berg" (el hombre pequeño y el gran monte). 
lo que recuerda que todavía el cine mudo no estaba lejos, en el que se concede más importancia a las imágenes y a las vistas panorámicas. Aunque la prensa la alabó, no como una ópera filmada, sino como una poesía épica y una balada en imágenes (Riefenstahl, 1987: 354-355), la propia directora, que veía la película completa por primera vez, se dio cuenta de que ni ella misma era adecuada para ese papel ni el estilo del film era actual (Riefenstahl, 1987: 525), entre otros motivos porque después de 1945 la fascinación para las películas de montaña había pasado de moda. La gente tenía otros problemas y, si se rodaban en las montañas, el interés se centraba más en temas técnicos, por ejemplo, en un embalse, una autopista, etc. (Spaich, 1994: 113-114).

Al final, Karajan tenía que dirigir la música fílmica, pero su cachet era demasiado elevado, por lo que la encargó a Herbert Windt, quien ya había compuesto la música para el film Olympia, añadiendo a la música de la ópera algunas danzas y músicas españolas (Quintana, 2002:3). Cuando la acción tiene lugar en la alta montaña o en el valle con los protagonistas principales se recurre a la música de la ópera; por el contrario, con la gente del pueblo, en el castillo o con los caballos y toros suena música típica española.

\section{Mujer}

La protagonista principal de Terra baixa/Tiefland es Marta. En el drama y la ópera cuenta con el apoyo de Nuri, una adolescente ingenua. Riefenstahl ha añadido a Amelia, la prometida de Sebastiano, como antagonista de Marta, mientras que Nuri ha sido sustituida por Josefa, una sirvienta anciana.

a) Marta: la protagonista fílmica difiere fundamentalmente de la del drama y la ópera. Para ello influyeron diversos factores, entre otros, sobre todo debido a que la figura de la Marta guimeraniana es un producto típico del siglo XIX. Sebastià, un hacendado rural, tiene que casarse con una heredera rica para salvarse así de la ruina. No obstante, está obsesionado por una pobre molinera huérfana, Marta, quien un mendigo había acogido de niña después de la muerte de su madre y con quien iba de pueblo en pueblo pidiendo limosna o bailando hasta llegar a las posesiones del cacique, quien la hizo su amante al mismo tiempo que dio un molino al mendigo. Marta no corresponde a su 
amor y de mala gana se somete a la violación. En el drama y la ópera, Sebastià/ Sebastiano es un terrateniente (Möller-Soler, 1988), mientras que en la película es un ganadero de toros, quien además ha sido elevado a la posición noble de marqués de Roccabruna. A pesar de tener que casarse para salvar su hacienda, no quiere renunciar de ninguna manera a Marta y, para guardar las apariencias, la obliga a casarse con un pastor inocente, Manelic/Pedro, quien vive aislado en la alta montaña. Después de la boda, el pastor se entera de la intriga y mata a Sebastià/Sebastiano con sus propias manos, tal como antes había hecho ya con un lobo. Reconciliado con su mujer, se marcha con ella a la alta montaña, símbolo de pureza y de sentimientos nobles en contraste con la tierra baja. En el drama y en la ópera se pone de relieve la situación miserable e indefensa de Marta, sobre todo cuando ella misma explica su destino lastimoso, que en la ópera da lugar a la famosa aria d'urlo: "Ich weiss es nicht, wer mein Vater war" ("No sé quién fue mi padre") (Lothar y d’Albert, 1931: 44-45).

En la película, rodada casi medio siglo más tarde, la posición de la mujer ha cambiado radicalmente así como también las figuras dickensianas de niños abandonados, indefensos y seducidos. Por su parte, ya la misma Riefenstahl incorporaba una personalidad completamente diferente con su profesión insólita para una mujer a principios de la historia del cinema (bailarina, actriz, directora y guionista). ${ }^{7}$ Como al final ella misma escribió el guion, lo adaptó a su idiosincrasia apartándose básicamente de la protagonista del drama y de la ópera, a la vez que introdujo y acentuó el tema social de la rebelión de los siervos (Riefenstahl, 1987: 356). La preproducción de Tiefland había empezado en 1933, pero la tuvo que interrumpir y, después de haber rodado Triumph des Willens, Olympia y empezado Pentesilea, al volver a trabajar con este tema, tal como ella misma confiesa, le resultó difícil identificarse con Marta (Riefenstahl, 1987: 354), cuya psicología es completamente opuesta a la de una Pentesilea.

En el drama y la ópera, antes de conocer a Manelic/Pedro, la figura de Marta es la de un personaje débil sin voluntad propia, quien a pesar de repugnarle tener que casarse con el pastor desconocido, se deja conducir

7 En esa época en Alemania había sólo otra directora de cine: Thea von Harbou (1888-1954), la mujer de Fritz Lang, quien escribió además muchos guiones para este. 
pasivamente hacia el altar. En la película, el carácter de Marta es más fuerte, en otras palabras su conducta corresponde más a la de una directora de cine que a la de una pobre molinera subyugada, de aquí que su consentimiento a la boda no resulta plausible. Por su parte, Sebastiano incorpora la plena convicción de un sentimiento indiscutible de poder absoluto (Hegel, 1970: 153), pero Marta no se deja arredrar ante él estando siempre dispuesta a plantar cara tanto al amo como al pastor; por ejemplo, cuando va por primera vez al castillo de aquel, el guitarrista, su acompañante, hace una reverencia al marqués, pero ella no; en otra ocasión impide al amo de pegar a una campesina o ayuda activamente a los campesinos contra el mismo cacique y, cuando este le regala unas joyas, las entrega a la molinera para que puedan pagar sus deudas. Cuando el molinero devuelve el collar al mayoral y el cacique la interroga, ella le dice la verdad y él la tira al suelo obligándola a ponerse el collar; en otra ocasión, cuando Sebastiano le pega a un subordinado y a continuación carga un fusil, Marta se interpone y le pregunta desafiante qué quiere hacer, lo que contribuye a que desista de disparar. Al principio, en el film, Marta no es molinera, sino Natario, pero, cuando el amo lo echa del molino porque no le paga, el cacique la hace molinera, lo que permite escenificar en el molino la secuencia final de la lucha entre Sebastiano y Pedro, igual que en el drama y la ópera.

aa) Baile: en la ópera, Marta, ya casada, baila a desgana obligada por Sebastiano, quien toca él mismo la guitarra y quiere humillarla ante su marido y la gente del pueblo. D'Albert y Lothar introdujeron esta escena para conferir color local con la guitarra, ya que en el drama original no aparece. Riefenstahl era bailarina profesional, y aunque un accidente en la rodilla le impidió que continuara esa carrera, bailaba a menudo en sus películas, y para Tiefland tomó lecciones de flamenco (Koebner, 1997: 186). La directora alemana procuraba siempre introducir color local no tan sólo en el paisaje y los edificios, sino también en los vestidos, así el de Marta como también el de los aldeanos recuerdan a las majas y campesinos goyescos. En el drama y la ópera, después de la muerte del mendigo, Marta continúa viviendo en el molino; por el contrario, en el film aparece por primera vez recién llegada al pueblo para bailar acompañada de un guitarrista con quien no tiene ninguna relación íntima y que pronto desaparece de la escena. Una vez en el pueblo, baja del carro y se 
ajusta los zapatos y las castañuelas. Al presentarla como bailarina profesional, le otorga automáticamente ciertas reminiscencias de mujer fatal, por quien los hombres se pierden como sucede también aquí (Koebner ha hecho observar cierto parecido con el pathos tétrico y estilizado de una versión de Carmen de una película negra). Al bailar en una taberna una danza española, que dura tres minutos, despierta los deseos de los hombres presentes e incluso un campesino llega a interpelarla. En esos momentos entra Sebastiano, mientras Pedro la observa a través de la ventana. Ya desde el principio despierta un fuerte arrebato pasional en el amo a la vez que también influye para que Pedro pueda construir su ideal abstracto de mujer pura (Quintana, 2002: 9). Al final, el cacique la invita a subir a su castillo, cuyo patio presenta reminiscencias de la Alhambra. Marta acude con el guitarrista para bailar, pero Sebastiano envía a éste a la cocina tocando él mismo la guitarra (igual como en la ópera). Aquí de nuevo Marta baila lasciva otra vez, lo que hace que el cacique le comente: "Der Tanz steht Dir im Blut" ("El baile lo tienes en la sangre"), con lo que no queda del todo claro quién seduce a quién. En los dos bailes, que tienen lugar en el film, es evidente que Marta atrae a propósito a Sebastiano, por lo que tiene más dominio sobre él.

ab) Triángulo pasional: la relación entre los tres personajes principales (Marta, el cacique y el pastor) se basa en una solución que se practicaba a menudo en las cortes europeas a fin de que el señor pudiese conservar a su favorita "legalizada" ante los ojos de la corte. ${ }^{8}$ En el caso de favoritas "legalizadas" normalmente éstas y el futuro marido se aprovechaban de la situación, ya que todos los implicados estaban de acuerdo. En el caso de Terra baixa/Tiefland, Marta no quiere y le repugna su posición y Manelic/Pedro entra en el trato totalmente inconsciente de la trama, que se urde a sus espaldas. Sin embargo, aunque la película se basa en ese mismo esquema, existen cambios esenciales; por ejemplo, en el drama y la ópera la solución del matrimonio fingido de la molinera procede de Sebastià/Sebastiano, mientras que en el film lo sugiere el

8 Eugenio d'Ors etiquetó La catalane (1907), una ópera francesa, que se basa también en Terra baixa, de "favorita rusticana" (1950: 489) por su semejanza con el tema de la ópera de Donizetti a nivel rural. También la novela Griego busca griega de Friedrich Dürrenmatt se basa en este tema si bien se cambia la dramática en una comedia. 
mayoral, y, como ya se ha indicado anteriormente, Marta es una mujer adulta muy segura de sus encantos, quien va al pueblo como bailarina profesional y pronto se da cuenta de su poder sobre el amo. Durante toda la película domina con su personalidad, por lo que es tratada con respeto y es interpelada con "Doña", cuya posición queda mucho más fuerte que la Marta infeliz y acobardada del drama y la ópera. Pedro y Sebastiano la conocen al mismo tiempo cuando baila, mientras que en el drama el amo concierta el matrimonio con el pastor sin que ambos se conozcan; y en la ópera, Sebastiano se presenta en el prólogo en la cabaña de Pedro acompañado de Marta, donde ambos se encuentran por primera vez Por su parte, el Pedro de Riefenstahl, aunque ingenuo, es un hombre muy interesante, como se demuestra cuando come con las criadas de Sebastiano. Muchas de esas se esfuerzan para atraer su atención, lo que presenta una diferencia fundamental entre el drama y la ópera, donde el pastor rústico no había tenido nunca contacto con ninguna mujer ni tan sólo había visto una de cerca.

b) Amelia: en el drama y en la ópera se habla de ella sin nombre como de la prometida de Sebastiano, en la película, Amelia corporeiza una mujer guapa e inteligente, pero dura y seca, consciente de su posición fuerte ante el cacique arruinado. Como conoce la existencia de Marta, exige que esta se marche. En el film se perfila muy claramente la postura de Sebastiano y Amelia, cuyos intereses son manifiestos: salvarse de la ruina para el cacique y el título nobiliario para Amelia, quien comentará: "Ein Bettler ist der Herr Marquis" ("Un mendigo es el señor marqués"). Durante una cena con Amelia, la cual se abanica muy folclóricamente, el amo le habla en primer lugar de su cría deficitaria de toros para pedirle a continuación que se case con él. El padre de ella tiene los comprobantes de las deudas del cacique, mediante los cuales le presionan para que se case con su hija y que al mismo tiempo eche a Marta. Ésta ya quería marcharse, pero el amo la obliga a quedarse y a casarse para guardar las apariencias. Cuando Amelia ordena que saquen a Marta, el mayoral dice que ya es fuera, puesto que ha partido por propia voluntad a escondidas de Sebastiano. Tanto en el drama como en la ópera, Sebastià/Sebastiano tiene relaciones con Marta antes de prometerse y, cuando el padre de su prometida se entera de la existencia de esta, deshace al acto los esponsales con lo que 
automáticamente arruina al cacique. Por el contrario, en la película el cacique conoce a Marta después de haber pedido la mano de Amelia. El padre de ésta es un calzonazos a manos de su hija, quien es la que decide a pesar de todo de casarse con el marqués. Como contraste, Riefenstahl se complace en presentar paralelamente las secuencias de las bodas dobles de Marta con Pedro y de la de Sebastiano con Amelia con el consiguiente banquete nupcial de estos últimos, el cual se celebra en el castillo acompañado de bailes de salón con una coreografía muy espectacular alrededor del surtidor del patio.

c) Entorno de Marta: en el drama y la ópera aparece el binomio MartaNuri. Esta última es una adolescente ingenua, antítesis de Marta, la cual hubiese sido también así, si Sebastiano no la hubiese seducido. Es la única del pueblo que está a favor de Marta y más tarde de Manelic/Pedro a la vez que respeta a Sebastiano como amo y señor. A través de ella se introduce un soplo de frescor y de inocencia en la atmósfera enrarecida de la tierra baja. Riefenstahl ha sustituido a Nuri por Josefa, una criada anciana de Sebastiano, quien acompañará a Marta a la iglesia para la boda, pero que nunca llegará a ser una confidente, si bien, de vez en cuando, levantará su voz, cual ángel justiciero, ante Marta a favor de los siervos oprimidos ni tampoco se arredrará a echar en cara al cacique el haber maltratado a Marta.

d) Aldeanas: Guimerà y d'Albert y Lothar presentan a las mujeres del pueblo como comadres maliciosas y curiosas, quienes se regocijan burlonas de la situación penosa de Marta y de la posición ridícula del pastor. La ópera acentúa la actitud socarrona de las mujeres a través de tres solistas, las cuales, a diferencia del drama, tienen nombre propio: Pepa (soprano), Antonia (mezzosoprano) y Rosalía (contralto), cuyos cantos son acompañados por una música de staccato con disonancias de los instrumentos de metal. Por el contrario, en la película, además de recurrir a muchos más comparsas (Riefenstahl 1987: 468-476), la actitud hostil de los campesinos se centra predominantemente contra el cacique y no contra Marta, que comprenden que los quiere ayudar. 


\section{Animales}

El tema de los animales ofrece una gama muy amplia para metáforas, metonimias, comparaciones y alegorías, en las cuales las propiedades de cada animal se confiere automáticamente a las personas. Ya en la Edad Media, los bestiarios y las fábulas con animales eran muy populares, y contribuyeron a consolidar las características específicas de cada animal; por ejemplo, el león, rey de los animales; el lobo, símbolo de codicia y estupidez, o el águila, soberana del aire. Tanto en el drama como en la ópera de Tiefland no está previsto que en el escenario aparezca ninguna clase de animales. Por supuesto, la escenografía depende siempre en último término del director de introducir o no algún animal, pero en los textos ninguno de ellos tiene un protagonismo activo. En la película aparecen muchos animales típicos de un pueblo de campesinos de la alta montaña; por ejemplo, palomas por la calle, gallinas en el patio del castillo, si bien el ojo de la cámara se centra principalmente en las ovejas, toros, caballos y mulos sin olvidar los perros de Pedro, Nando y Sebastiano; y como salvajes, el lobo - protagonista principal-y las águilas. Además de la presencia física de estos animales es interesante de observar la relación de estos con los protagonistas.

\section{a) Domésticos}

aa) Perros: en primer lugar, los perros son los guardianes de sus amos y de retruque también de las ovejas de estos. En el drama, Manelic relata que el lobo mataba a menudo sus perros: "un gos pernes enlaire" ("un perro piernas arriba") (Guimerà, 1975: 1400); en el prólogo de la ópera, Pedro hace referencia a "mein braver Hund" ("mi buen perro") (Lothar y d'Albert, 1931: 14). En la película aparecen muchos perros, y con pequeños detalles la directora muestra su empatía por esos animales; por ejemplo, el perro de Pedro tiene nombre (Tara), y después de que Pedro ha matado el lobo, lava primero las heridas del perro antes de curar las suyas. También a los perros les confiere un sexto sentido para descubrir a los buenos y malos de la película, así Tara recibirá a su amo con alegría y será a través de sus ladridos que Pedro descubrirá a Marta desmayada; 
por el contrario recibirá amenazadora a los siervos de Sebastiano cuando van a buscar a Marta; por su parte, el perro de Sebastiano ladrará al guitarrista de Marta, pero no a ésta.

ab) Ovejas: las ovejas son consideradas como símbolo de inocencia y de paz y también como emblema del cristianismo. Dado que Manelic/Pedro es un pastor, es obvio que tenga un rebaño de ovejas, si bien Riefenstahl las utiliza al mismo tiempo para realzar el escenario bucólico, a la vez que juegan un papel importante como víctimas del lobo y también como nutrición de sus amos; por ejemplo, como detalle curioso, cuando Pedro baja al pueblo con algunas ovejas, se asa un cordero en la cocina de Sebastiano donde comen las sirvientas del castillo, que invitan a Pedro. Una metáfora de las futuras relaciones de Marta y Pedro con reminiscencias bíblicas (el buen pastor) aparece en una secuencia, donde un cordero se ha encaramado encima de una roca inaccesible y no puede bajar. El pastor arriesga su vida para salvarla y entregarla a continuación a la oveja madre así como antes las había defendido matando al lobo.

ac) Caballos/mulos: Riefenstahl se esforzó en introducir elementos típicos de España, entre otros caballos y toros. Una secuencia muy folclórica es el paseo en caballo de Marta y Sebastiano, que recuerda a la feria de abril de Sevilla. En realidad, Minetti, quien interpretaba a Sebastiano, fue doblado para montar a caballo por Peter Jacob, un oficial de caballería.

ad) Toros: tanto en el drama como en la ópera, Sebastiano es un terrateniente; por el contrario, Riefenstahl para conferir color local de acuerdo con clichés turísticos lo convirtió en un ganadero de toros. La directora alemana estaba acostumbrada a rodar escenas multitudinarias (Olympia, Triumph des Willens), por lo que aquí introduce el paso de una manada de toros con más de seiscientos animales (Riefenstahl, 1987: 392).

\section{b) Salvajes}

ba) Lobo: en la tradición literaria-popular occidental la figura del lobo se utiliza a menudo como símbolo de violencia, fuerza y maldad, y a veces representa también al diablo. Ya en la Ilíada (XVI, 352-355) como también en la Biblia (Gén. 49, 27; Jer. 5, 6) y en el Nuevo Testamento (Mt. 7, 15), aparece como una fiera feroz, 
enemigo innato de las ovejas. En el drama y la ópera evidentemente no aparece ningún lobo en el escenario, sólo Manelic/Pedro narra retrospectivamente una lucha mortal, que sostuvo con uno, que despedazaba sus ovejas así como también las de Nando. Esta narración retrospectiva servirá de parábola en el más estricto sentido evangélico de la palabra para anunciar la metamorfosis final en la que el pastor mata al cacique (Benet i Jornet, 1974: 569-572).

Para una perfeccionista como era Riefenstahl, resultaba evidente que había de rodar con un lobo de verdad, si bien necesitó tres lobos hasta encontrar por fin a uno que le sirviera (Riefenstahl, 1987: 360-361). Al empezar la lucha con Pedro, este primero le tira una piedra, y cuando el lobo le muerde la mano, combaten cuerpo a cuerpo, estrangulándole con sus propias manos. Después del combate, sale el sol, lo mismo que al final de la película como símbolo del triunfo de las fuerzas del Bien sobre las del Mal. Igual en el drama y la ópera, Pedro regala la piel del lobo muerto al cacique, quien le da un duro como recompensa. Por su parte, la lucha del pastor contra el lobo es un nexo de enlace metafórico entre Sebastiano (lobo) y Pedro (pastor), ya que ese último mata a un lobo verdadero para posteriormente estrangular al cacique, como lobo metafórico. Según su concepción del mundo, cuando el pastor se entera de la intriga urdida por Sebastiano, no le queda otra opción que matar al "lobo", que ha herido a su "oveja". El drama de Guimerà acaba con el grito triunfal de Pedro: “He mort el llop”» (“¡He matado al lobo!”) (1975: 1427), repetido tres veces. Acompañada por los acordes de una música triunfal apoteósica de toda la orquesta, la ópera acaba con un aria de Pedro (Lothar y d'Albert, 1931: 63), con leitmotivs musicales que glorifican la tierra alta sin hacer ninguna referencia a la muerte de Sebastiano ni tampoco a la metáfora del lobo. En la película, ya antes de la lucha, Pedro asocia al amo con aquel animal: "Du bist der Wolf!" (“ ¡Tú eres el lobo!”) y una vez muerto el cacique, la pareja sube a la tierra alta enmarcada por una escenografía muy estilizada en la que las montañas y el sol adquieren el protagonismo principal.

bb) Águila: un animal típico de alta montaña es el águila real, que puede volar en pocos segundos hasta tres quilómetros de altura. Se considera al águila como la reina del aire debido a su vuelo majestuoso por las altitudes aéreas inalcanzables, planeando por encima de los humanos a la vez que se admira 
la magia de su mirada. Goza de una imagen francamente positiva, ya que por ejemplo es el símbolo del evangelista san Juan y su efigie figura en muchos escudos nacionales. Riefenstahl, como alpinista apasionada, conocía bien la fauna de estas regiones y era consciente de su simbología, por lo que también las introdujo en el film, las cuales contribuyen a poner una nota de movimiento en las alturas en contraposición con la inmovilidad de las montañas.

\section{Naturaleza}

a) Montaña: tanto en la tradición oriental como en la occidental la montaña es un lugar de encuentro entre los humanos y la divinidad. Montes sagrados pertenecen a todas las teologías, por ejemplo, el Gólgota, el Carmelo, el Fujiyama, el Hira (cerca de La Meca), el Olimpo, etc. En su cima se realiza el deseo de los humanos de buscar inspiración transcendental y también el hecho de escalar hacia el cielo representa una liberación de las tribulaciones de la vida cotidiana (Spaich, 1994: 109). Que las montañas sean un símbolo de espiritualidad se debe en parte a su topografía aislada y elevada, cerca del cielo, junto con las fatigas propias del subir (dimensión vertical). Por su parte, el alpinismo forma parte de las experiencias modernas de entrar en contacto con el paisaje y también como símbolo de comprensión estética. Antes del siglo XVIII, los montes se consideraban como macizos de difícil acceso, repletos de regiones agrestes. Por su parte, los románticos, y en Cataluña sobre todo los modernistas, estaban fascinados de su belleza excepcional. El drama guimeraniano presenta la dicotomía de la alta montaña en contraposición con la tierra baja, donde tiene lugar la acción desde un punto de vista realista rural. Un gran terrateniente de Matadepera (cerca de Barcelona) inspiró la figura de Sebastià, pero se supone que Guimerà situó la acción más bien en Queralbs en los Pirineos catalanes (Miracle, 1958: 403). Para captar la atmósfera del paisaje alpino, d'Albert y Lothar hicieron excursiones al Monte Rosa (Raupp, 1930: 167) dando una visión romántica, pero no poética, de la alta montaña de acuerdo con los cánones veristas.

Tiefland se alinea en la tradición de las películas de montaña alemanas

típicas de los años veinte en las que la naturaleza desempeña un protagonismo 
activo (Diederichs, 1994: 166). Ese tema permitía salir de los límites estrechos del escenario, sobre todo en las secuencias de la tierra alta. La esencia del cine es la dramaturgia de la naturaleza, por lo que algunos críticos opinaban que para haya cine, hay que situarlo en un lugar del universo, siendo el decorado un problema estético del teatro filmado (Bazin, 1977: 104). Riefenstahl aprovechó al máximo el lenguaje fílmico de la alta montaña contrarrestando cielo y montes mientras que el paisaje de la tierra baja es desolado, llano, casi lunar. La tierra árida es el espacio de la realidad, mientras que la montaña es el espacio de los ideales (Quintana, 2002: 9). La película se rodó en cinco lugares diferentes: en Krün, cerca del Mittelwald en el macizo de Karwendel de los Dolomitas, hizo construir el pueblo. Para la cabaña de Pedro se decidió por un altillano de Ciampedi, también en los Dolomitas, donde tiene lugar la lucha con el lobo. Para filmar el paso de los toros eligió Las pedrizas, cerca de Madrid. Para los interiores, los estudios de Berlín y para el final, los estudios Barrandov de Praga durante los últimos días de la guerra. Algunas secuencias de la película presentan reminiscencias de Der heilige Berg, por ejemplo, la subida al monte de Marta, en la que va a parar a la cabaña de Pedro, quien la pone en su cama desmayada, recuerda el ascenso de Diotima a la montaña, si bien en una situación no tan dramática, pero que acaba también en la cabaña del alpinista o de Stürme über den Montblanc, donde Hella Armstrong visita de sorpresa la cabaña del metereólogo Hannes.

\section{b) Agua/sequía}

ba) Agua: siguiendo la tradición de las películas de alta montaña, el agua juega un papel estético importante confiriendo color local alpino a la vez que sirve de elemento de purificación y refresco. Riefenstahl se recrea en poner de realce la belleza estética del agua en movimiento (riachuelos, cascadas, torrentes) y también del agua mansa de un lago cerca de la cabaña de Pedro, el cual fue creado artificialmente ya que en aquel lugar no había ninguno (Riefenstahl, 1987: 386). El agua cristalina de las fuentes de alta montaña adquiere un papel importante como bebida (igual que en Der heilige Berg); por ejemplo, cuando Marta despierta de su desmayo en la cabaña de Pedro la primera cosa que 
pide es agua; Pedro ofrece también agua a Nando, otro pastor, cuando éste le viene a visitar o él mismo bebe del agua pura y cristalina de un arroyo. El agua domesticada del surtidor del patio del castillo aparece a menudo en primer plano, ya sea como motivo estético, ya sea como parte de la coreografía del baile de las fiestas de la boda del cacique, ya sea para realzar la injusticia social como contraste con la sequía que sufren los siervos.

El agua, como uno de los temas centrales, no aparece en absoluto ni en el drama ni tampoco en la ópera. Un motivo de ello se puede buscar en que la escenificación de ese elemento como tal es difícil de representar igual que el mar (Baccar, 1991: 157-186). En el drama, Marta menciona una presa de agua, donde quería suicidarse (Guimerá, 1975: 1390) o Nuri enumera las posesiones de Sebastiano, entre ellas un riachuelo (Guimerá 1975: 1387). En la ópera, la molinera hace referencia de pasada al embalse donde no tuvo el valor suficiente para tirarse (Lothar y d'Albert, 1931: 22), sin precisar dónde, y Nuri relata con detalle las pertenencias del amo, incluyendo todas las aguas corrientes de la alta montaña: ríos, riachuelos y cataratas (Lothar y d'Albert, 1931: 17).

bb) Sequía: para la preproducción de la película, Riefenstahl había visitado diferentes lugares de España, sobre todo la España seca, y también había ido a Mallorca para fotografiar los molinos (1987: 219). Además de presentar el agua bajo su aspecto estético, introdujo también una vertiente social: la penuria de agua de los siervos de Sebastiano, que falta completamente en las versiones dramática y operística. La única fuente del pueblo para beber es el agua del pozo; para conseguir un pequeño cubo para cada uno, los aldeanos tienen que hacer pacientemente una larga cola, naturalmente con caras largas. Mientras la cámara muestra los campos de los alrededores, que se secan, aparece una manada de toros, que beben el agua, que servía para regar los campos de los siervos. En esos momentos, Sebastiano y Marta pasan a caballo entre la gente desesperada por la carencia del agua. Riefenstahl aúna la metáfora del agua con la maldad de Sebastiano, ya que una vez ese muerto, se resuelve el problema de la sequía con la lluvia. Koebner llamó la atención sobre el conflicto políticosocial de Tiefland, que también suele encontrarse a menudo en las películas del oeste americano, en las que el amo desprovee a los siervos del agua con la consiguiente revuelta de estos y la muerte del tirano (1997: 186). En la película, 
la actitud de los siervos contra Sebastiano es más animosa y hostil que en el drama y la ópera, donde no se trata del problema del agua, pero sí se acentúa más el aspecto geográfico y social (confrontación pueblo bajo/montaña) (MöllerSoler, 1988: 148).

bc) Nubes/lluvia/temporal: las nubes denotan a menudo una devastación potencial (temporal, diluvio, inundación), que produce miedo y desasosiego a la vez que sirven de trasfondo siniestro y misterioso, aunque también estético. Al principio de Tiefland, la cámara enfoca un pico con unas nubes, la cuales se adosan pintorescamente a la montaña como si fuesen su sombra confiriéndole cierto relieve, y la próxima toma presenta al lobo en primer plano con el cielo encapotado como trasfondo. Con sus formaciones las nubes se prestan muy bien para representar imágenes; por ejemplo, cuando Pedro sube del pueblo a la montaña, el cielo está cubierto de nubes, las cuales se disuelven dibujando el rostro de Marta, que el pastor acaba de ver por primera vez bailando en el pueblo. Por otro lado, el cielo se hallará nublado cuando Pedro baja para casarse con Marta como presagio siniestro de lo que se le espera en la tierra baja.

Por su parte, la lluvia se considera como signo de fertilidad y vida, pero también de castigo, el cual puede llegar incluso hasta la muerte (por su dirección vertical, de arriba a abajo, representa plásticamente, cual espada de Damocles, una amenaza destructora de todo lo que se halla por debajo), a la vez que puede servir de metáfora para expresar el estado de ánimo de un personaje o de una situación. Es un elemento difícil de escenificar en el teatro, pero no en una película: al final, durante la fiesta de la boda, estalla una tormenta, la cual causa tal miedo y terror a los invitados del castillo, que se marchan todos corriendo. También Sebastiano abandona el banquete luchando obcecadamente contra la lluvia y el viento, que sopla recio por las calles, para ir donde Marta en el molino. Es una marcha sin retorno ya que allí le espera la muerte. Mientras tanto ésta ha revelado a su marido la intriga urdida contra él. La primera reacción de él es la de regresar solo a la montaña en medio de la noche y del temporal, pero ante las súplicas y lágrimas de su mujer, queda indeciso y al final no se va, besando a su mujer como reconciliación. En esos momentos aparece Sebastiano e inmediatamente empieza el combate cuerpo a cuerpo entre ambos hombres acompañado por un trasfondo de truenos, rayos y viento, al compás 
del traqueteo siniestro de la rueda del molino como metáfora visual y acústica de los sentimientos de los tres protagonistas. De todos modos, como Benet i Jornet ha observado con acierto, una vez muerto Sebastiano, Manelic/Pedro se libera, pero Marta pasa como propiedad de un amo al otro (1974: 28), en ese caso de su marido.

Como antítesis del temporal y mal tiempo, Riefenstahl recurre al sol para realzar escenas triunfales; por ejemplo, éste saldrá después de que Pedro mate al lobo y más tarde a Sebastiano, y también para describir los estados anímicos de los protagonistas, por ejemplo, después que Pedro ha visto a Marta por primera vez en el pueblo, dirá: "Die Sonne für mich allein scheint" ("El sol luce para mí sólo"). Por el contrario, en el drama guimeraniano, como obra rural, falta cualquier referencia simbólico-estética a ese astro. También en la ópera tiene cierto protagonismo, por ejemplo, cuando Pedro baja al pueblo para casarse, le interpela: "O Sonne, nun leuchte mir auf meinem Weg zum Glück!” (“ $¡ O h$ sol, ilumina ahora el camino hacia mi felicidad!”) (Lothar y d'Albert, 1931: 14). Por su parte, Koebner quiere ver en ese final una restitutio in integrum, y en Pedro, una réplica de la figura de Junta de Das blaue Licht, quien de la mano de Marta se dirige hacia un mundo mágico, si bien es evidente, empero, de que se trata de un paraíso artificial (1997: 185).

\section{Referencias bibliográficas}

BACCAR, Alia Bornaz (1991): La mer, source de création littéraire en France au XVII siècle (1640-1671). París: Papers on Seventeenth Century Literature.

BAZIN, André (1977): “Theater and Cinema”. John Harrington (ed.), Film And/As Literature. Englewood Cliffs: Prentice Hall, pp. 93-105.

BENET I JORNET, Josep Ma (1974): “Terra baixa, un discurs sobre la propietat”. En Serra d’Or. Núm. 180, pp. 569-572.

BENTLEY, Eric (1974): "Realism and the Cinema". En Hurt, James (ed.), Focus on Film and Theater. Englewood Clffs: Prentice Hall, pp. 51-58. 
DIEDERICHS, Helmut H (1994): "Natur in der frühen deutschen Filmtheorie". En Jan Berg y Kay Hoffmann (eds.), Natur und ihre filmische Auflösung. Marburg: Timbuktu, pp. 161-173.

FRICKE, Harald (1985): "Schiller und Verdi. Das Libretto als Textgattung zwischen Schauspiel und Literaturoper”. En Jens Malte Fischer (ed.), Oper und Operntext. Heidelberg: Winter, pp. 95-115.

GUIMERÀ, Àngel (1902): Martha of the Lowlands. Trad. al inglés del español de Wallace Gillpatrick. Nueva York: Doubleday.

GUIMERÀ, Àngel (1975): Obres completes. Tomo I, Barcelona: Selecta.

HACKS, Peter (1980): Oper. Múnich: DTV.

HEGEL, Georg Wilhelm Friedrich (1970): Phänomenologie des Geistes. Werke 3. Fráncfort: Suhrkamp.

KAINDL, Klaus (1995): Die Oper als Textgestalt. Perspektiven einer interdisziplinären Übersetzungswissenschaft. Tubinga: Stauffenberg.

KIRSCH, Fritz Peter (2004): “Terra baixa, Tiefland und das Österreichsbild des Rudolph Lothar”. En Marisa Siguán y Karl Wagner (eds.), Transkulturelle Beziehungen: Spanien und Österreich in 19. und 20. Jahrhundert. Ámsterdam, pp. 27-35.

KOEBNER, Thomas (1997): "Der unversehbare Körper. Anmerkungen zu Filmen Leni Riefenstahls”. En Knut Hickethier, Egon Müller y Rainer Rother (eds.): Der Film in der Geschichte. Berlín: Sigma: pp. 178-199.

KRACAUER, Siegfried (1971): “Die Angestellten”. En Schriften. Vol. 1, Fráncfort: Suhrkamp: pp. 205-304.

KRACAUER, Siegfried (1979): Von Caligari zu Hitler. Fráncfort: Suhrkamp.

LINDENBERGER, Herbert (1984): Opera. The Extravagant Art. Ítaca: Cornell University Press.

LOTHAR, Rudolph y Eugene d’Albert (1931): Tiefland. Berlín: Bote\&Bock. 
MANVELL, Roger (1979): Theater and Film. Londres: Associated University Press.

MIRACLE, Josep (1958): Guimerà. Barcelona: Aedos.

MÖLLER-SOLER, Maria-Lourdes (1988): “Caciquisme i color local a 'Terra baixa' d'Àngel Guimerà i a 'Tiefland' de Rudolph Lothar i d'Eugen d'Albert”. En Zeitschrift für Katalanistik. Núm. 1, pp. 132-149.

NEUMANN, Petra (1999): Untersuchungen zu Werk und Rezeption des katalanischen Dramatikers Àngel Guimerà. Fr'nacfort: Lang.

ORS, Eugeni d'(1950): Obra completa catalana. Glosari 1906-1910. Barcelona: Selecta.

PANGELS, Charlotte (1981): Eugen d'Albert. Wunderpianist und Komponist. Eine Biographie. Zúrich: Atlantis.

QUINTANA, Àngel y Margarita Casacuberta (2002): El nacionalismo como mito: 'Tiefland' de Leni Riefenstahl, una interpretacion de 'Terra baixa' de Guimerà. Alicante: Biblioteca virtual Miguel de Cervantes, pp. 1-10.

RAUPP, Wilhelm (1930): Eugen d'Albert. Lipsia: Koehler\&Amelung.

RIEFENSTAHL, Leni (1945-1954): Tiefland. Dir. y prod. Leni Riefenstahl.

RIEFENSTAHL, Leni (1987): Memoiren. Múnich: Knaus.

SCHENK, Irmbert (2003): "Flucht aus der Moderne? Fanck, Riefenstahl, Trenker”. En Thomas Koebner, Norbert Grob y Bernd Kiefer (eds.), Diesseits der 'Dämonischen Leinwand'. Neue Perspektiven auf das späte Weimarer Kino. Múnich: Edition text kritik, pp. 327-340.

SCHMIDT, Helmut. (s. f.): The Exciting Life and Art of Leni Riefenstahl. En línea.

SOLER, Maridès (2007): “Les adaptacions operístiques de 'Terra baixa' d’Àngel Guimerà al francès ('La catalane') i a l'alemany ('Tiefland')". En Jordi Jané i Lligé y Johannes Kabatek (eds.): Fronteres entre l'universal i el particular en la literatura catalana. Aquisgrán: Shaker, pp. 25-44. 
SOLER, Maridès (2008): "De com Manelic va esdevenir Pedro". Temporada d’Òpera 2008-2009. Barcelona: Amics del Liceu, pp. 28-30.

SPAICH, Herbert (1994): “Bergwanderungen”. Jan Berg y Kay Hoffmann (eds.), Natur und ihre filmische Auflösung. Marburgo: Timbuktu, pp. 161-173.

UNVERRICHT, Hubert (1976): "Das Berg- und Gebirgsmilieu und seine musikalischen Stilmittel in der Oper des 19. Jahrhunderts". En Heinz Becker (ed.): Die 'Couleur locale' in der Oper des 19. Jahrhunderts. Ratisbona: Bosse, pp. 100-119.

ZIERAU, Ulla (1994): Die veristische Oper in Deutschland. Fráncfort: Lang. 